\title{
A MATEMÁTICA DIANTE DA POSSIBILIDADE DO ENSINO REMOTO: uma discussão curricular
}

\author{
SILVIA ELIANE DE OLIVEIRA BASSO \\ Instituto Federal do Paraná (IFPR). Mestre em Educação (UEM). Doutoranda em Educação, \\ (UEM). Especialista em História do Mundo Contemporâneo (UNIPAR). Graduada em \\ Pedagogia (UEM). Graduada em História (UNIPAR, 1993). Professora de História e \\ História da Educação no IFPR - Campus Umuarama/PR. ORCID: 0000-0002-2015-2437. \\ E-mail: silviabasso_2005@hotmail.com

\section{NETÚLIO ALARCON FIORATTI} \\ Instituto Federal do Paraná (IFPR). Engenheiro Civil (UNESP). Mestre (UNESP). Professor \\ no Instituto Federal do Paraná (IFPR) - Campus de Umuarama-PR - e Coordenador do \\ Curso Técnico em Edificações Integrado ao Ensino Médio. ORCID: 0000-0001-8713-165X. \\ E-mail: netulio.fioratti@ifpr.edu.br
}

\section{MARIA LUISA FURLAN COSTA}

Universidade Estadual de Maringá (UEM). Doutora em Educação (Unesp/Araraquara). Mestre em Educação (UEM). Graduada em História (UEM). Professora Adjunta do Departamento de Fundamentos e Práticas da Educação (DFE/UEM) e do Programa de Pós-Graduação em Educação (PPE/UEM). Líder do Grupo de Pesquisa Educação a Distância e as Tecnologias Educacionais/CNPQ. ORCID: 0000-0002-7838-0459. E-mail: luisafurlancosta@gmail.com 


\section{A MATEMÁTICA DIANTE DA POSSIBILIDADE DO ENSINO REMOTO: uma discussão curricular}

Este trabalho tem por objetivo colaborar nas discussões curriculares para o ensino de matemática evocando as teorias críticas e pós-modernas como forma de questionamento das tradições de conteúdo e metodologias. Considera-se nesta análise a atualidade da pandemia mundial da COVID-19, doença infecciosa provocada por vírus, e os poucos ou inexistentes debates para a construção da Base Nacional Comum Curricular e a Reforma do Ensino Médio, que no momento colocam em xeque o êxito das propostas diante da fragilidade dos sistemas educacionais públicos, no que concerne às ferramentas e conhecimentos para aulas e ensino remoto. Para tanto, parte-se das problematizações de currículo que sempre existiram e neste momento tornam-se cada vez mais necessárias e importantes, chegam-se às discussões sobre o ensino de matemática como conteúdo cultural e como possível ferramenta para o desenvolvimento da capacidade de crítica social de quem a estuda e a ensina, ambos por meio de estudos já publicados. Assim, aludindo a discussões que hibridizam teorias críticas e pós-modernas, a matemática sai da esfera de conteúdo hegemônico, permitindo-se reconstrução para abordagem dos mais diferentes temas, sem que perca espaço para suas prescrições específicas da ciência de orientação. É a matemática posta no campo das incertezas, para permitir-lhe ampliar a compreensão das inúmeras situações em que tratamento de dados e modelagens possam estar à serviço de justiça ou injustiça social. Apresenta-se, na sequência, relato de experiência com um exemplo de metodologia de ensino de conteúdo de matemática por meios digitais, como forma de ilustrar possibilidades, avaliação de potencialidades e fornecimento de subsídios para a discussão. Por fim, são consideradas na experiência registrada, as potencialidades e as adversidades ligadas ao ensino de matemática de forma remota e corrobora-se a necessidade do debate em torno do currículo que inclua não só pesquisadores, mas principalmente professores e estudantes, num ensino de matemática que envolva sua natureza, fundamentos, significados e consequências no cotidiano.

Palavras-chave: Ensino de Matemática. Currículo. Pandemia. Ensino Remoto.

\section{THE MATHEMATICS IN FRONT TO THE POSSIBILITY OF REMOTE TEACHING: a curricular discussion}

This work aims to collaborate in the curricular discussions to the mathematics teaching evoking the critical and postmodern theories as a way to question the contents and methodologies. Its is considered the topicality of the world pandemic of COVID-19, infectious disease provoked by a vírus, and the few or nonexistents debates to the construction of the Common Curricular Nacional Base and the Reform of the Hight School, which in this momnt put in check the success of the proposals in face of the fragility of the public educational system regarding to the tools and knowledge for the classes and remote teaching. Therefore, we start from the curriculum problems that have always existed and at this moment become increasingly necessary and important, we come to discussions about mathematics teaching as cultural content and as a possible tool for the development of the social criticism capacity of those who study and teach it, both through studies already published. Thus, alluding to discussions that hybridize critical 
and postmodern theories, mathematics leaves the field of hegemonic content, allowing reconstruction to approach the most diverse subjects, without losing room for its specific prescriptions of the guidance science. It is the mathematics put in the field of uncertainties, to allow broaden understanding of the countless situations in which data processing and modeling may be at the service of justice or social injustice. Hereafter, it is shown an experience report with an example of a methodology for teaching mathematical content by digital media, as a way of portray possibilities, evaluating potentialities and providing subsidies for the discussion. Finally, the potentialities and adversities associated with teaching mathematics remotely are considered in the recorded experience and suports the need for debate around the curriculum that includes not only researchers, but mainly teachers and students, in a mathematics teaching that involves its nature, fundamentals, meanings and consequences in daily life.

Keywords: Math Teaching. Curriculum. Pandemic. Remote Teaching.

\section{LA MATEMÁTICA DELANTE DE LA POSIBILIDAD DE LA ENSEÑANZA REMOTA: una discusión curricular}

Este trabajo tiene el objetivo de colaborar en las discusiones curriculares para la enseñanza de matemática evocando las teorías críticas y posmodernas en forma de cuestionamento de las tradiciones y metedologías. Se toma en cuenta la actualidad de la pandemía mundial de la COVID-19, enfermidad infecciosa causada por vírus y a los pocos o inexistentes debates para la construcción de la Base Nacional Comun Curricular y la Reforma de la Escuela Secundaria, que en el actual momento pone en jaque el éxito de las propuestas delante de la fragilidad de los sistemas públicos educacionales con respeto a las herramientas y conocimientos para clases y enseñanza remota. Para estos fines, se parte de las problematizaciones del currículo que siempre existieron y en esto momento se han convertido como más necesarias e importantes, se llega a las discusiones sobre la enseñanza de matemática como contenido cultural y como herramienta posible para el desarrollo de la capacidad de crítica social de quién la estudia y la enseña, ambos por medios de estudios ya publicados. Así, aludiendo a las discusiones que hibridizan teorias críticas y posmodernas, la matemática sale de la esfera de contenido hegemónico, se permitiendo reconstrucción para enfoques de los más diversos temas, sin la pérdida de espacios para sus prescripciones específicas de la ciencia de orientación. Es la matemática puesta en el campo de las inseguridades, para le permitir ampliar la comprensión de las numerosas situaciones en que el tratamineto de datos y modelados puedan estar a servicio de la justicia o injusticia social. Tras eso, se presenta un relato de experiencia con un ejemplo de metodología de enseñanza de contenido de matemática por los medios digitales, de manera a ilustrar posibilidades y suministros de subsidios para la discusión. Por último son consideradas, en el registro de la experiencia, el potencial y las adversidades relativas a la enseñanza de matemática de forma remota y se corrobora la necesidad del debate acerca del currículo que incorpore no sólo investigadores, sino principalmente profesores y estudiantes, en una enseñanza de matemática que implique su naturaleza, fundamentos, significados y consecuencias en el cotidiano.

Palabras clave: Enseñanza de Matemática. Currículo. Pandemia. Enseñanza Remota.

\section{plurais}




\section{A MATEMÁTICA DIANTE DA POSSIBILIDADE DO ENSINO REMOTO: uma discussão curricular}

\section{Introdução}

Tradicionalmente visto como um rol de disciplinas ou matérias escolares, dispostas em tempos e espaços previstos em um planejamento, currículo tem sido naturalizado na escola como se sempre estivesse estado lá daquela forma, sendo possível pensar em sua organização ou propor-lhe modificações apenas quando políticas governamentais instituem essa necessidade.

Assim, o que se ensina em cada uma das disciplinas, e mesmo suas especificidades, parecem não ser questionáveis mesmo para aqueles que cursaram uma licenciatura e teoricamente deveriam ter sido formados para refletir, construir e organizar um currículo conjuntamente com outros profissionais. Ao chegar a uma escola o novo professor (que pode ser também o professor novo), recebe um planejamento, um guia didático, instruções sobre o funcionamento da instituição, papeladas e prazos e, quando consciente, sensibilizada e com liberdade (de tempo e espaço) para esse trabalho, a equipe pedagógica lhe ofertará uma formação, que será formação permanente na sequência do trabalho.

Tais condições são as ideias que nem sempre se encontram nas escolas públicas de grande parte do país, quiçá nas particulares, que o fazem com um compromisso de mais cumprir também as imposições de um currículo cujo ciclo fecha-se no resultado de desempenho de exames nacionais ou de ingresso à universidade, que as escolas rankeam, garantindo a satisfação dos clientes e a chegada de novos.

Essa mesma pressão chega à escola pública que vai sendo (des)classificada em exames oficiais e rankeada nos índices de aprovação daquilo que definiu-se por especialistas como conteúdo a ser ensinado, assim como, para que ensinar.

Neste artigo, objetiva-se problematizar o currículo em tempos de aulas remotas e distanciamento social que colocou escolas sob a pressão de estar "presente" na distância exigida por uma pandemia mundial provocada pela doença infecciosa COVID-19, neste ano de 2020. Sempre em 
destaque como medida de sucesso educacional, a disciplina de matemática é alvo de preocupações, pois o que e como ensina, pode ser feito de forma remota?

Tentando responder a essas várias questões, parte-se das problematizações de currículo que sempre existiram, ficam emergentes neste momento, chega-se às discussões sobre o ensino de matemática como conteúdo cultural, ambos por meio de estudos já publicados, e apresenta-se, por meio de relato de experiência, um exemplo de metodologia de ensino de conteúdo de matemática por meios digitais como possibilidade de desenvolvimento de autonomia de aprendizagem ao estudante.

\section{O Currículo em questão}

Desnaturalizando o currículo, o que significa historicizá-lo, pode-se dizer que desde que a escola em qualquer nível se organizou para ensinar, isto é planejou conteúdos, métodos, objetivos, temos currículo. Pautados em valores desejáveis para a comunidade ou agrupamento que representavam, especialistas estabeleceram o que ensinar, para que e como. No Brasil esses primeiros especialistas foram os jesuítas e alguns conteúdos eram vistos como úteis para ampliar a memória ou facilitar o raciocínio lógico. Isso não é um problema, é história, o problema é naturalizar isso e continuar fazendo da mesma forma ad aeternum.

Em Saviani (2003) se encontra uma definição de currículo que não resume seu significado, mas oferece um ponto de partida para a reflexão por trazer elementos que são plausíveis para qualquer grupo:

O currículo diz respeito a seleção, seqüência e dosagem de conteúdos da cultura a serem desenvolvidos em situações de ensino-aprendizagem. Compreende conhecimentos, idéias, hábitos, valores, convicções, técnicas, recursos, artefatos, procedimentos, símbolos etc... dispostos em conjuntos de matérias/ disciplinas escolares e respectivos programas, com indicações de atividades/ experiências para sua consolidação e avaliação. (SAVIANI, 2003, p.01).

Pautando-se no pesquisador espanhol Gimeno Sacristan, Saviani utilizará a compreensão de currículo como processo envolvendo ações de entes dentro e fora da organização escolar. Assim há âmbitos de ações burocráticas (órgãos educacionais), mercadológicas (editoras de livros) e pedagógicas (professores), com relativa autonomia em relações de dependência mas também de incoerência, sendo, portanto, o currículo, objeto de políticas e táticas para mudá-lo.

\section{plurais}


Em Teorias de Currículo Lopes e Macedo (2011), realizam trabalho sinóptico de abordagens para a discussão sobre Currículo. Com sinóptico, no entanto, não se quer dizer reduzido, pois o livro se apresenta como um compêndio de autores e teorias no tratamento do assunto. $\mathrm{O}$ currículo é então, um campo em disputa, em que uma fixação mínima de sentidos permite refletir para além das tradições postas.

De acordo com as mesmas autoras a primeira referência ao termo currículo registra-se em 1633 na Universidade de Glasgow significando curso inteiro seguido pelos estudantes, assim "currículo dizia respeito a organizar a experiência escolar de sujeitos agrupados" (LOPES e MACEDO, 2011, p.20).

Tendo sido abordado de inúmeras maneiras desde quando a escola tornou-se uma necessidade na sociedade industrial, o currículo tornou-se nas últimas décadas alvo constante de discussão por à ele vincularem-se conhecimento, cultura e organização social.

Em países cujas políticas de bem-estar social tão relevantes após a $2^{\mathrm{a}}$ guerra mundial passam a ser questionadas e as vertentes econômicas do neoliberalismo vão pautar um discurso do eficientismo, mérito individual e empreendedorismo, o currículo na escola passa por ressignificações que serão questionadas por educadores como Michael Apple que é personagem, narrador e também crítico da escola básica norte-americana a partir das décadas de 1970 e 1980. É neste contexto histórico que faz o questionamento de a quem ou o que o currículo atende. Nesta forma de estudar o currículo como campo em disputa, a pergunta mais significativa para o autor não é "qual conhecimento tem mais valor" e sim "de quem é o conhecimento que tem mais valor". (APPLE, 2006, p.21).

Pergunta instigante e que pode causar estranheza a quem não está familiarizado com este tipo de discussão, mas que é absolutamente pertinente se considerarmos que não há neutralidade em educação, como afirmava o pensador Paulo Freire (1921 - 1997) em inúmeros de seus textos, em que educar é uma ato político (FREIRE, 2007). Afirmar a neutralidade pode ser na verdade corroborar com o que está posto, mas foi posto ali por algum motivo. Recriar currículos em que grande parcela da população e cultura estava fora da escola como se isso fosse bom é nas palavras de Apple, uma "revolução que anda para trás": 
Tendemos a esquecer que as "revoluções podem andar para trás". O que estamos testemunhando na educação e em muitas outras instituições econômicas, políticas e culturais é exatamente isso - uma política que quer mudar radicalmente nossa sociedade para que ela espelhe um paraíso supostamente existido um dia. Bem, esse "paraíso" foi a época em que alguns comentaristas mais atentos chamaram de "moinho satânico" e de uma política de controle cultural que de fato marginalizou as vidas, os sonhos e as experiências das pessoas. (APPLE, 2006, p.12).

Referindo-se à crítica do sociólogo húngaro Karl Polanyi (1888-1964) às graves consequências sociais que o processo de instrumentação industrial provocou na sociedade "triturando homens e transformando-os em massa", Apple incita a questionar discursos da escola boa de antigamente num posicionamento em que a cultura está em posição central para a análise da sociedade e do currículo.

Fazendo o percurso histórico do Currículo como campo nos Estados Unidos, o autor ajuda a pensar também a realidade em que nos encontramos. O autor salienta que as discussões sobre currículo se intensificam nos EUA no seu crescente processo de industrialização do início do século XX, ameaçando o modelo social pautado na classe média rural. A chegada de milhares de imigrantes somada à população negra que vinha do sul do país, tanto quanto a nova elite de industriais, cria, para este setor da sociedade norte-americana, o temor pela mudança no estilo de vida.

Sem conseguir conter a imigração, e portanto a cultura que lhe é inerente, os teorizadores do currículo desviarão a discussão do campo das diferenças étnicas para o campo da ciência e da técnica. A ciência defendendo a superioridade da nacionalidade americana (e não de qualquer americano), quando por exemplo, pesquisas antropológicas alegavam que os negros tinham uma propensão a formas de governos monárquicas e não democráticas e a tecnologia e técnica administrativa mostrava a excelência da produtividade e progresso econômico. A essa categoria de pessoas dominantes da técnica e da ciência cabia um tipo de currículo e ao restante da população outro.

Finney adotou uma visão de diferenciação um pouco diferente daquela dos teóricos formativos da área. Defendia o que parecia ser um currículo comum em que predominavam as disciplinas emergentes da ciência social, mas fez uma distinção fundamental de como esses temas deveriam ser ensinados a indivíduos de diferentes habilidades. Os de alta inteligência aprenderiam sobre sua herança social por meio de um estudo das ciências sociais. Seria um estudo que os ensinaria não apenas sua herança, mas as demandas sociais nela implicadas. Aos indivíduos de inteligência inferior seriam ensinadas apenas as

\author{
plurais \\ Salvador, v.5, n.2 p.192-213, mai/ago. 2020
}


próprias ciências sociais, mas isso seria condicionado a responderem chavões adequados que refletissem o conteúdos dessas disciplinas e as demandas sociais nela contidas. (APPLE, 2006, p. 123).

Brasil, 2016, pós-impeachment de Dilma Roussef, o então Presidente Michel Temer lança por meio de Medida Provisória - MP n 746/2016 (BRASIL, 2016) uma reforma com mudanças drásticas para o ensino médio brasileiro. $\mathrm{O}$ fato de lançar-se como medida provisória e tão imediatamente após o impeachment já demonstra uma articulação prévia de grupos e parlamentares que desconsiderava o caminho que vinha sendo traçado pela educação nacional desde a Lei de Diretrizes e Bases da Educação Nacional - LDB n 9394/96 (BRASIL, 2017). Esta, não só estabelecia princípios para uma educação humanitária, como lançava os percursos para o Plano Nacional de Educação (PNE), com ampla discussão e participação nacional dos mais diversos setores da sociedade.

Sem ser esse o objeto de discussão neste trabalho, a menção a este fato remete a análise feita pela pesquisadora Monica Ribeiro da Silva (SILVA, 2019), coordenadora do Observatório do Ensino Médio da Universidade Federal do Paraná (UFPR) e Movimento Nacional em Defesa do Ensino Médio, quando afirma que a medida provisória transformada em Lei ${ }^{\circ}$ 13.415/2017 (BRASIL, 2017), mesmo após amplo movimento de ocupações de escolas públicas em todo país ${ }^{1}$, a Base nacional Comum Curricular - BNCC (BRASIL, 2019a) e reformulação das Diretrizes Nacionais para o Ensino Médio - DCNEM / Resolução MEC nº 03/2018 (BRASIL, 2019b), como três atos de um só golpe que desrespeitam o que vinha sendo delineado pelo PNE e Diretrizes Nacionais - DCNEM/2012, e impõe arbitrariamente uma formação reducionista, limitada e recortada em itinerários formativos.

Um dos itinerários formativos é o de matemática e suas tecnologias, sendo também a disciplina de matemática e de língua portuguesa as obrigatórias nos três anos do ensino médio, independente do itinerário escolhido, que pode ser também: linguagens e suas tecnologias, ciências da natureza e suas tecnologias, ciências humanas e sociais aplicadas e formação técnica e profissional.

Desde o ano 2000 a Organização para Cooperação e Desenvolvimento Econômico (OCDE) promove uma avaliação para estudantes de 15 anos de idade a todos os países membros. É o PISA - Programa Internacional de Avaliação de Estudantes e as áreas avaliadas são leitura, matemática

1 O movimento de ocupações de escolas liderado por jovens articulados nas escolas ou pela União Brasileira de Estudantes Secundaristas (UBES) registrou mais de mil escolas ocupadas em todo o país, na defesa da ampla discussão e suspensão da reforma. 
e ciências. Os resultados apontam que o Brasil permanece entre os 10 piores resultados em matemática, na última avaliação em 2018, e mantiveram as médias de resultado entre os 20 últimos para ciências e leitura (G1.GLOBO/EDUCACAO, 2019).

Todas essas discussões e números em avaliações são questões essenciais para a área de currículo que no contexto atual tornam-se ainda mais intensas, pois como afirma Apple (2006), o currículo não está neutro ao contexto:

A educação está intimamente ligada à política da cultura. O currículo nunca é apenas um conjunto neutro de conhecimentos, que de algum modo aparece nos textos e nas salas de aulas de uma nação. Ele é sempre parte de uma tradição seletiva, resultado da seleção de alguém, da visão de algum grupo acerca do que seja conhecimento legítimo. É produto das tensões, conflitos e concessões culturais, políticas e econômicas que organizam ou desorganizam um povo. (APPLE, 2006, p.59).

Assolados mundialmente pela enfermidade COVID-19, o contexto de pandemia de 2020 interrompeu a presencialidade das aulas por todo o globo. São milhões de estudantes em casa nas mais diversas condições socioeconômicas, mas todos sob a mesma ameaça: a contaminação, disseminação e ameaça à vida que o vírus provoca.

Num país com imensas desigualdades sociais como o Brasil, o cenário para a continuidade do ensino e da aprendizagem de milhares de estudantes é dramático. Com as aulas presenciais suspensas desde o mês de março de 2020, muitas Secretarias Estaduais e Municipais de Educação, passaram a planejar e aplicar programas emergenciais de ensino remoto por meio de entrega de materiais impressos, aulas gravadas, atendimentos online via plataformas digitais ou aplicativos de celulares. Além das graves questões de falta de acesso de grande parte da população a esses mecanismos de comunicação virtual e internet, ou pior, a ausência absoluta de políticas públicas sanitárias em forma de falta de água encanada, passaram muitos docentes a questionar a possibilidade de ensino e aprendizagem de uma disciplina como a matemática, de forma remota.

Enunciado o contexto atual e o mote das discussões curriculares, passa-se na próxima seção à reflexão das (im)possibilidades do ensino e a aprendizagem de conteúdos de matemática de forma remota.

\section{p/ullais salvador, v.5, n.2 p.192-213, mai/ago. 2020}




\section{Ensino remoto em tempos de pandemia: a matemática em foco}

Básica para a vida cotidiana, para a aprovação em qualquer tipo de exame ou concurso, para medir o nível de qualidade da escolarização de um país, a matemática é, ou parece ser, condição sine qua non na construção de conhecimentos básicos para a vida em sociedade e, portanto, "indiscutível" no currículo escolar, tanto que a BNCC (2017) tem nela um de seus itinerários e é uma das disciplinas obrigatórias para todos os anos do ensino médio.

Realizando discussão para pensar o currículo em matemática, que deveria ser o caminho para a construção de Diretrizes Nacionais em lugar da BNCC obrigatória, Silva (2013) apresenta a tradição do currículo fordista de planejamento linear e conhecimento transmitido resultante da $2^{\mathrm{a}}$ Revolução Industrial (1850-1945), em dissonância com a necessidade de construir novos critérios para a escolha e organização de conteúdos matemáticos para o ensino médio brasileiro.

Tecendo a problematização de currículo, Silva (2013) apresenta as abordagens críticas e pós-modernas como coerentes com as discussões acadêmicas e, acrescenta-se, com os movimentos estudantis, de questionar a finalidade do ensino médio e o papel da matemática nesse processo.

Os estudos sobre ensino de matemática e educação matemática, entre eles os de etnomatemática de D'Ambrósio (200--?)², de ideias fundamentais da matemática de Machado (2014) e de matemática crítica de Skovsmose (2001), compõem a série de pesquisas, ainda escassas na área da educação matemática, que convidam os professores e os estudantes a encarar a matemática e seu currículo, como meios através dos quais a crítica sobre a conformação social pode ser realizada.

A etnomatemática de D’Ambrósio (20--?) é um conceito que extrapola aquilo que está no "etno" comumente utilizado até o momento em outras áreas. Etno era compreendido como as particularidades pelas quais determinado grupo concebia uma área ou conhecimento, o que a tornava "menor" em relação aos modelos clássicos ocidentais. Na abordagem de D'Ambrósio, etnomatemática é a matemática no contexto dos grupos humanos, e assim, as de todos os povos e tempos estão nela, não sendo correto "julgar" a matemática dos povos da Amazônia, por exemplo, a partir da grega clássica (D’AMBRÓSIO, 20--?).

2 O texto utilizado neste trabalho está hospedado na página de um grupo de pesquisa de uma Universidade, não constando a data de sua publicação. Desta forma optou-se por inseri-lo por ser basilar, apresentando-o por meio da norma Abnt /Nbr 6023/8.6.2, listada a referência ao final deste trabalho. 
Para Machado (2014) o grande problema no ensino de matemática (como de outras áreas) da sociedade contemporânea, é a fragmentação de conteúdos que faz com que estudantes (principalmente no ensino médio) recebam centenas de "pontos" de matemática, acreditando-se que ao final tem-se o todo. Isso não acontece: a fragmentação dilui o interesse e os estudantes saem com uma grande quantidade de pontos e sem as ideias fundamentais da matemática. Nas revisões curriculares, discutem-se pontos e não as ideias fundamentais que sempre extrapolam a organização em disciplinas.

Essas abordagens classificadas como críticas, são apresentadas ao lado das chamadas pós-modernas por Silva (2013) numa proposta de hibridização teórica para pensar o currículo de matemática. De acordo com o autor, as abordagens críticas tensionam o papel da educação e do currículo trazendo para os conteúdos o questionamento de sua função na resolução dos problemas sociais e a disputa de poder, procurando aproximar os estudos de um conteúdo cultural, reconhecidamente hegemônico e direito de todos. Temos as pesquisas de Ole Skovsmose do movimento da matemática crítica (SKOVSMOSE, 2001), com referência capaz de dar uma dimensão reflexiva à disciplina.

Nas abordagens pós-modernas a complexidade, o afastamento da visão binária de opostos: possível / impossível ou certo / errado, cria milhões de possibilidade de abordagens e aprendizagens numa disposição do conteúdo em rede, na perspectiva de ser sempre transformado, num constante processo de significação / ressignificação de conceitos, valores e atitudes. Um dos autores citados nessa abordagem Doll Jr.(1997).

A hibridização proposta por Silva (2013) pauta-se na chamada práxis da incerteza dos pesquisadores norte-americanos David Stinson e Erika Bullock, que considera: "aspectos das ações transformadoras da perspectiva crítica em harmonia com a incerteza e a complexidade da corrente pós-moderna". Assim o autor hibridiza o compromisso social da matemática, sem atestar-lhe conteúdos hegemônicos, ao mesmo tempo em que por meio da constante reconstrução permite a abordagem dos mais diferentes temas, defendendo simultaneamente espaço para as orientações específicas da ciência de orientação (SILVA, 2013, p. 227).

\footnotetext{
plurais 
Sem pretender fazer de seus 8 Rs $^{3}$ uma prescrição para organização curricular, Silva apresenta tal abordagem para pensar a matemática nessa realidade intitulada de incertezas e colaborar no debate educacional.

Os estudos sobre matemática crítica, especialmente aqueles apresentados por Skovsmose (2001) em "Educação matemática crítica: a questão da democracia", alertam que os modelos matemáticos são aquilo que formatam o mundo e, portanto, são utilizados para tomadas de decisão das intervenções humanas neste mundo. É muito corriqueira a utilização de uma linguagem matemática nas relações de comércio, nas situações de produção de bens, nas prestações de serviço, nas situações de cadastro propriedades imóveis e em muitas outras relações que são de natureza social. São relações que existem basicamente devido à capacidade humana de criar e cultivar socialização e relacionamentos de benefícios mútuos.

Apesar da linguagem matemática ser muito utilizada nas relações humanas de primeira ordem não se limitam a elas, muito pelo contrário, em outras relações humanas mais complexas residem as maiores intervenções e consequências também tratadas através da linguagem matemática, que são as decisões políticas e as atitudes do mercado financeiro.

As políticas públicas sempre são decididas com base em indicadores que são apresentados em linguagem matemática: a matemática é exata, mas sua aplicação não é neutra, o que não pode garantir que os dados apresentados são os únicos e os mais indicados a serem levados em conta para cada situação. É possível que os dados possam ser tratados sob outras perspectivas, que a matemática, que até então foi considerada anunciadora da verdade, possa ter sido também um instrumento em que prevaleça a vontade de alguns.

É neste contexto, que o currículo que trata do processo educativo que envolve elementos de natureza matemática, precisa ser visto como elemento que pode ser utilizado para que se mantenha uma visão distorcida das realidades ou que esta visão seja contestada. Desta forma, aquilo que é ensinado em matemática, o currículo da matemática, pode ser visto como uma ferramenta de governo dos outros (BAMPI, 2000).

3 Terminologia usada e desenvolvida pelo autor a partir dos estudos de Doll Jr., para a abordagem híbrida do conteúdo em Matemática: riqueza, reflexão, realidade, responsabilidade, recursão, relações, rigor e ressignificação. 
Quando se ensinam ferramentas matemáticas para tratamento de dados e modelagem do mundo natural, ensina-se ao estudante que ele pode realizar intervenções e aumentar sua compreensão do mundo natural ou mesmo do mundo alterado pelo homem, mas pouco se ensina que modelagens e tratamentos parecidos são os mesmos utilizados por aqueles que governam os seres e os entes que compõe a sociedade. Esta pequena visão já é proporcionadora de grandes mudanças na maneira com que se observa a matemática e pode ser ampliada quando se direciona o olhar para o sem número de injustiças sociais que são construídas e mantidas diariamente.

Esta práxis do ensino da matemática, esta forma de manifestar o currículo de matemática no processo pedagógico, pode existir em correlação com aquilo que é entendido como currículo praticado (currículo em ação), mas pode não ficar restrita apenas a esta compreensão de currículo. Pode-se expandir também aos currículos normativos, aos currículos dos planejamentos e a tantas outras formas de compreender o currículo, seja em suas perspectivas estritamente acadêmicas como em suas perspectivas mais diretamente tangentes à vida cotidiana da grande maioria dos cidadãos.

No universo da sala de aula, é comum percebermos estudantes definindo-se entre "de humanas" ou "de exatas". Parece que houve um esquecimento da história da evolução dos processos do pensamento humano. Os grandes pensadores da antiguidade eram pensadores não exclusivamente dos números, mas da matemática da realidade, ao mesmo tempo que eram pensadores da condição humana. Uma educação matemática que retome os conceitos matemáticos como inerentes à condição humana e necessários para a construção de processos cognitivos consistentes é tão imprescindível que percebe-se isso exposto claramente no texto da BNCC:

Um dos desafios para a aprendizagem da Matemática no Ensino Médio é exatamente proporcionar aos estudantes a visão de que ela não é um conjunto de regras e técnicas, mas faz parte de nossa cultura e de nossa história. [...] Assim, as habilidades previstas para o Ensino Médio são fundamentais para que o letramento matemático dos estudantes se torne ainda mais denso e eficiente, tendo em vista que eles irão aprofundar e ampliar as habilidades propostas para o Ensino Fundamental e terão mais ferramentas para compreender a realidade e propor as ações de intervenção especificadas para essa etapa. (BNCC, 2017, p. 522).

Muito atual é a avaliação da progressão do número de infectados em uma epidemia bem como o comportamento típico da curva de contágio, evolução do número de óbitos, efetividade

\section{plurais}


de tratamentos e muitos outros dados que inundam os meios de comunicação em um período no qual se materializa uma pandemia. Porém, tão importante quanto perceber que a matemática está no desenho daquilo que acontece é tão importante quanto encontrar as funções ou determinar o polinômio interpolador que parece descrever determinado fenômeno, é perceber que a matemática per se é neutra, mas nas relações humanas, nas situações inegavelmente reais que governam realidades e produzem muitas alegrias e sofrimentos, nada é inócuo.

A matemática está também nas análises das variáveis e indicadores para tomadas de decisões de políticas públicas em saúde, no fluxograma do funcionamento de um processo de compras públicas e na maneira com que recursos escassos são distribuídos, privilegiando um ou outro, contribuindo para a manutenção de uma realidade ou a construção de outra. Quando os indivíduos são educados para governarem a si de forma autônoma, libertadora e crítica, a matemática tem papel fundamental neste processo educativo.

\section{Possibilidades do ensino remoto da matemática}

Educação à distância, ensino a distância, aulas remotas, atividades não presenciais... inúmeros termos emergem nesse momento em que, sem possibilidades de retorno das comunidades escolares, que representavam diariamente aglomerações de centenas de pessoas: estudantes, docentes, técnicos e demais servidores, aconteçam. Instituições particulares, primeiramente, e as públicas na sequência, instituíram ou ampliaram no caso de cursos $\mathrm{EaD}$, o uso de ferramentas para re(estabelecer) uma "regularidade" de relação docente / discente; instituição / comunidade e a possibilidade de ensino / aprendizagem.

Sem ser objeto específico deste trabalho, é oportuno observar que as instituições particulares saem quase de forma imediata na oferta desse serviço, algumas já com as condições e a experiência, mas todas elas pressionadas pelo perigo do não pagamento do serviço suspenso - é a expressão da educação transformada em mercadoria.

Na esteira desse procedimento, as instituições públicas são chamadas à manifestar-se e então haverá respostas das mais variadas e nenhuma delas alcançando a totalidade dos estudantes, pois na escola pública estão os estudantes que expressam condições socioeconômicas das mais graves. 
Partindo dessas considerações, faz-se uma breve apresentação das definições das terminologias para o ensino não-presencial e apresenta-se uma experiência de atividade para ensino remoto de conteúdo da matemática, experimentado no Instituto Federal do Paraná (IFPR) Campus Umuarama, com uma turma da matéria de Topografia do curso Técnico em Edificações Integrado ao Ensino Médio, no período de 13/04/2020 a 30/04/2020.

Respeitando as pesquisas e experiências na área e objetivando dar clareza à descrição da atividade, recorre-se aos pesquisadores da área que subsidiam o entendimento do assunto, tanto quanto a normativa do IFPR para as atividades nesse contexto. Assim têm-se:

a) Educação a Distância - modalidade conhecida pela sigla EaD, como tipo de configuração para o ensino-aprendizagem, formas de organização administrativa, técnica, logística e pedagógica da educação (MILL, 2018, p.198-199);

b) Ensino remoto ou aula remota: modalidade de ensino ou aula que pressupõe distanciamento geográfico de professores e estudantes, com transposição do ensino presencial físico para os meios digitais, com foco na informação e suas formas de transmissão, predominantemente de maneira síncrona (MOREIRA; SCHLEMMER, 2020, p. 8-9);

c) Ensino a Distância: ensino caracterizado pela separação física e, por vezes temporal, entre alunos e professores, vinculado a um meio de comunicação, desde a escrita à utilização de microcomputadores e Web (MOREIRA; SCHLEMMER, 2020, p. 10-13);

d) Atividades pedagógicas não presenciais (APNP): ações de caráter formativo relacionadas aos projetos pedagógicos dos cursos ofertados pelo IFPR desenvolvidas externamente aos ambientes educativos da instituição e sem a interação direta entre educadores e educandos. (IFPR, 2020, p.02).

Desse modo, como atividade pedagógica não presencial, aproximando-se do que do que Moreira e Schlemmer (2020) caracterizam como ensino remoto, uma possibilidade de ensino a distância, passa-se a descrição da atividade.

A matemática é um contexto de ensino onde existe grande dificuldade de ruptura de seus métodos tradicionais de trabalho. Os professores e professoras de matemática construíram-se

\author{
plurais


através desses métodos tradicionais, tanto durante a educação básica, quando em sua formação docente. Para muitas pessoas a educação matemática tendo como objetivo o ensino de elementos que fazem parte da natureza matemática só é alcançada pelas vias tradicionais, onde se ensinam as regras, os métodos, os algoritmos, as sequências lógicas de forma objetiva e quase positivista.

Quando se pretende auxiliar o estudante na apropriação de conceitos de natureza matemática, quando o objetivo é caminhar para uma alfabetização matemática, os elementos estritamente tradicionais podem e precisam ser flexibilizados através da inclusão de elementos do cotidiano do estudante e que permitam a evolução de sua capacidade crítica.

Exemplos sem muitas conexões com a realidade cotidiana certamente tem seu valor, especialmente quando se trata do que Silva (2013, p. 214) chamou de "valorização do conhecimento matemático historicamente construído, da Matemática pela Matemática", porém não se pode deixar de ter em mente que todo um processo educativo em matemática, baseado na Matemática pela Matemática, tende mais à distanciar os educandos que acolhê-los.

Objetivando, então, manter vivo o processo de alfabetização matemática em tempos de distanciamento social devido à pandemia, é que a referida atividade foi elaborada. Pretendeuse utilizar ferramentas cotidianas para maior parte dos estudantes, então, através da plataforma Google Sala de Aula, onde todos os estudantes já estavam inseridos, foi disponibilizado um texto curto introdutório e um documento de texto (Google Docs) previamente preenchido, em que os estudantes deveriam seguir um roteiro e preencher as informações em locais previamente sinalizados, informações estas que seriam obtidas através do Google Maps diretamente ou através da interpretação de alguns dados.

Por se tratar da matéria de Topografia, atentando-se que um curso integrado trabalha conceitos de todas as disciplinas de forma integrada, foi escolhido o tópico da ementa que trata de "posicionamento orbital e geoprocessamento". O objetivo da atividade era fazer uma revisão integrada de conceitos já trabalhados na geografia, como cartografia, e plano cartesiano e pares ordenados na matemática direcionados para a compreensão inicial do funcionamento do Sistema de Posicionamento Global (Global Positioning System - GPS). 
Inicialmente foi apresentada aos estudantes uma imagem que remete a uma cena do episódio final de temporada, de um seriado popular entre o público adolescente e adulto. Nesta imagem a personagem deveria resolver um enigma e assim descobrir uma coordenada geográfica, que descobriu-se ser onde seu par romântico estava esperando. Nesta escolha há a intenção de trazer a atenção do estudante para a atividade por tratar-se de uma produção de entretenimento amplamente divulgada em mídias específicas e em redes sociais, além de trazer a questão do enigma, que pode não ter ficado claro para quem assistiu e traz curiosidade para quem não assistiu.

Figura 1: Imagem com enigma mostrando coordenadas geográficas.

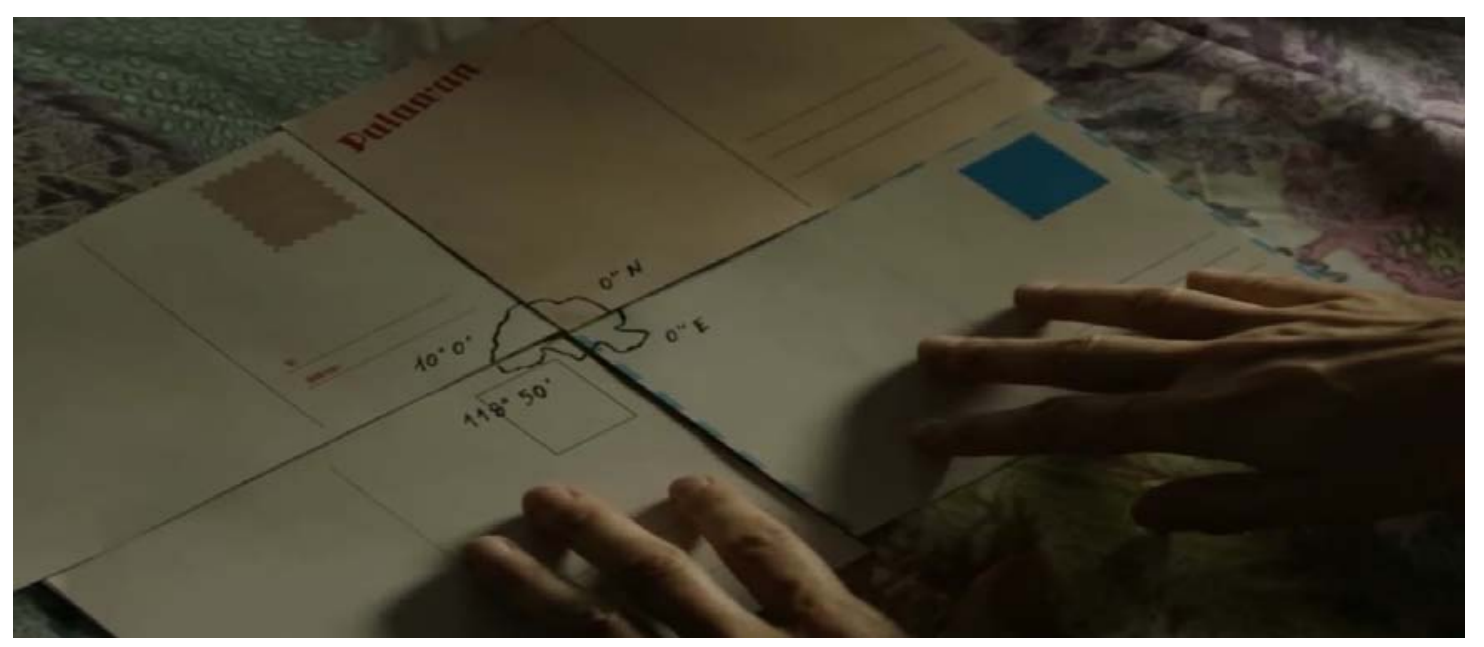

Fonte: “La casa de papel”, Netflix, temporada 2, episódio 9, 40’15”"4

De posse desta coordenada geográfica, o roteiro da atividade solicitava ao estudante inicialmente a conversão das coordenadas, que são ângulos no formato sexagesimal, para o formato decimal. A operação de transformação do ângulo foi ensinada em uma aula síncrona simples que foi disponibilizada também assíncrona para ser vista novamente, se o estudante considerasse necessário. Este é um tópico quase que exclusivo de matemática, sem tanta conexão com cotidiano. Neste ponto do roteiro de atividade o docente também abordou a importância das diversas formas

4 Disponível em: https://www.netflix.com/watch/80205395?trackId=14277281\&tctx=0\%2C $\%$ 2C 88899 b52-ee07-45e5-bca1-d57abba73ad2-106555931\%2C\%2C\%2C

\footnotetext{
plurais 
de expressar uma grandeza e ainda a precisão dos algarismos decimais significativos, que para serem compatíveis com a precisão de segundos do formato sexagesimal, demandam serem em grande quantidade.

Após, é feito um paralelo entre o GPS e o plano cartesiano, sendo o cruzamento da linha do equador com o meridiano de Greenwhich o ponto de origem do plano cartesiano, isto é, as coordenadas geográficas, em formato sexagesimal acrescida das letras indicadoras dos hemisférios são convertidas em coordenadas cartesianas, em formato decimal com valores positivos indicando norte nas latitudes e leste nas longitudes, e valores negativos indicando sul nas latitudes e oeste nas longitudes. A análise do plano cartesiano em paralelo com o sistema de posicionamento global contextualiza em muito o formato cartesiano com a realidade do estudante, ampliando a possibilidade de compressão da utilidade dos conceitos trabalhados.

Para concluir o início da atividade o estudante deveria, utilizando o Google Maps inserir as coordenadas em formato sexagesimal e em formato decimal, encontrar o local indicado na imagem do seriado, fazer print da tela e colar no roteiro de atividades. Como atividade de fixação o estudante deveria encontrar diversos outros locais, com coordenadas apresentadas no roteiro com os dois formatos mencionados.

Paralelamente a estas atividades, também foi necessário trabalhar a utilização de separadores de decimais, que nos Estados Unidos, onde o GPS foi criado e ainda é mantido, o separador de milhar é a vírgula e o separador de decimal é o ponto, situação contrária à utilizada no Brasil.

Para conclusão geral, os estudantes foram convidados a procurar um lugar no mundo que gostariam de apresentar na atividade, tirar um print da tela e escrever suas coordenadas geográficas no formato sexagesimal e decimal, novamente como exercício de fixação dos conceitos estudados. A avaliação do aprendizado foi feita através da resposta das diversas fases da atividade e também das respostas dos estudantes nas devolutivas que o professor realizou.

Para trabalhar este assunto em aula presencial da referida matéria, o docente utilizaria um conjunto de 2 horas-aula, foi disponibilizado mais tempo ao estudante por questões de dificuldades de acesso, ambientação na plataforma e desconhecimento do docente sobre a situação emocional dos estudantes dado o, então recente, início da pandemia. 
Apesar de inicialmente parecerem poucos os conteúdos da matemática no objetivo da atividade, convém salientar que a atividade contempla assunto de três disciplinas diferentes, associado ao fato de que se pretende manter o estudante atento à conceitos de natureza matemática além de apenas ensinar conteúdo matemático. Isto posto, é conveniente observar todos os outros conceitos matemáticos e elementos de natureza matemática que são trabalhados no decorrer da atividade, mesmo não estando explícitos no objetivo inicial.

Ao término da atividade, após realizada a avaliação de aprendizagem e do cumprimento do objetivo, pôde-se realizar um balanço das potencialidades e fragilidades da tentativa de ensinar conteúdos de natureza matemática remotamente.

Um primeiro aspecto que demanda atenção do docente é a questão da escrita matemática. É notável que esta atividade não privilegiou o desenvolvimento da comunicação escrita de conceitos de natureza matemática, isto é, da construção da linguagem matemática escrita do estudante e aí se materializa um dos maiores desafios do ensino remoto da Matemática.

Quanto aos conceitos objetivos da matemática, da geografia e da topografia que se pretendeu trabalhar, é possível observar através das respostas fornecidas à atividade que houve sim a compreensão, mas a observação direta do professor sobre a forma do estudante organizar inicialmente o tratamento do problema assim como a maneira com que o estudante desenvolve o tratamento do problema para chegar a uma solução, para responder a questão proposta, avaliações indispensáveis no processo educativo da matemática, não puderam ser realizada de forma satisfatória através desta atividade.

\section{Considerações finais}

A discussão sobre o currículo é uma das mais árduas e necessárias no contexto educacional, não por acaso é nela de maneira interventiva que a reforma do ensino médio tem sido conduzida no Brasil, nos últimos anos, por meio de medida provisória, documento de base sem ampla participação das "bases" e legislação na contramão das discussões nacionais dos pesquisadores em educação e educadores de maneira geral.

O contexto de pandemia mundial, estendido para além de um tempo inicial de expectativa, está sendo substituído por uma necessidade de agir de alguma forma e tem instigado (ou deveria) 
o debate sobre o currículo com suas implicações de que e para quem estão estes ou aqueles conteúdos e como são abordados.

A disciplina de matemática fazendo parte de todos os repertórios de avaliação internacionais e nacionais, com suas pontuais finalidades, depara-se com formas tradicionais, quase "sacralizadas" de ensinar, e a necessidade de encaminhar atividades de forma remota, fazendo emergir as teorias críticas e pós-modernas de concepção curricular na matemática.

A BNCC do Ensino Médio, até o momento texto não operacionalizado, pode ser questionada quando a atividade aqui apresentada como possibilidade de ensino de forma remota, demonstra a importância da integração, que embora preconizada pela BNCC pode apresentar-se como irrealizável diante de itinerários recortados e sem a presença de outras áreas científicas para estudantes que ainda estão realizando a alfabetização científica.

Assim, diante da ingerência de setores e atores empresariais na educação; diante de políticas públicas que propõem práticas fadadas a não realizar a qualidade e aproveitamento que teoricamente defendem; diante de um cenário em que o planejamento para trabalho na escola desconsidera a participação de seus trabalhadores, cada professor e cada estudante possa se perguntar: Quem sou eu diante da reforma curricular e da necessidade do ensino remoto? Esse, considera-se, já é um importante ponto de partida, para participar das tensões do currículo.

\section{REFERÊNCIAS}

APPLE, Michael. Ideologia e Currículo. 3.ed. Porto Alegre: Artmed, 2006.

BAMPI, Lisete. Currículo como tecnologia de governo de cidadãos e cidadãs. In: REUNIÃO ANUAL DA ANPED, 23., 2000, Caxambu. Textos completos dos trabalhos [...]. [S. l.: s. n.], 2000. Tema: GT 12 - Currículo, Disponível em: http://23reuniao.anped.org.br/textos/1207t.PDF. Acesso em: 26 jun. 2020.

BRASIL. Ministério da Educação. Base Nacional Comum Curricular - BNCC - etapa ensino médio. Disponível em: http://portal.mec.gov.br/index.php?option=com docman\&view $=$ download\&alias $=85121$-bncc-ensino-medio\&category_slug $=$ abril -2018 pdf\&Itemid=30192. Acesso em: 20 jan. 2019.

BRASIL. Lei ${ }^{0}$ 9.394, de 20 de dezembro de 1996. Estabelece as diretrizes e bases da educação nacional. Diário Oficial da União, Brasília, DF, 23 dez. 1996. Disponível em:< http://www. planalto.gov.br/ccivil_03/leis/L9394.htm>. Acesso em: 06 nov. 2017. 
BRASIL. Medida Provisória $n^{\circ}$ 746. Institui a Política de Fomento à Implementação de Escolas de Ensino Médio em Tempo Integral, altera a Lei n ${ }^{\circ}$ 9.394, de 20 de dezembro de 1996, que estabelece as diretrizes e bases da educação nacional, e a Lei no 11.494 de 20 de junho 2007, que regulamenta o Fundo de Manutenção e Desenvolvimento da Educação Básica e de Valorização dos Profissionais da Educação, e dá outras providências. Diário Oficial da União, Brasília - DF, sexta-feira, 23 de setembro de 2016.

BRASIL. Lei no 13.415, de 16 de fevereiro de 2017. Altera as Leis nos 9.394, de 20 de dezembro de 1996, que estabelece as diretrizes e bases da educação nacional, e 11.494, de 20 de junho 2007, que regulamenta o Fundo de Manutenção e Desenvolvimento da Educação Básica e de Valorização dos Profissionais da Educação, a Consolidação das Leis do Trabalho - CLT, aprovada pelo Decreto-Lei no 5.452, de 1 o de maio de 1943, e o Decreto-Lei no 236, de 28 de fevereiro de 1967; revoga a Lei no 11.161, de 5 de agosto de 2005; e institui a Política de Fomento à Implementação de Escolas de Ensino Médio em Tempo Integral. Disponível em: http://www. planalto.gov.br/ccivil_03/_Ato2015-2018/2017/Lei/L13415.htm. Acesso em: 14 de mar. 2017.

BRASIL. Resolução n⿳ 3, de 21 de novembro de 2018. Atualiza as Diretrizes Curriculares Nacionais para o Ensino Médio. Disponível em: http://www.in.gov.br/materia/-/asset_publisher/ Kujrw0TZC2Mb/content/id/51281622. Acesso em: 5 de mai. 2019

D’AMBROSIO, Ubiratan. O que é etnomatemática. Laboratório de Estudos e Pesquisa Transdisciplinares - LEPTRANS - Universidade Federal Rural do Rio de Janeiro. Disponível em: http://www.ufrrj.br/leptrans/textos.htm. Acesso em: 10 mai. 2020.

DOLL JR., W. E. Currículo: uma perspectiva pós-moderna. Tradução de Maria Adriana Veríssimo Veronese. Porto Alegre: Artes Médicas, 1997.

FREIRE, Paulo. Pedagogia da autonomia: saberes necessários à prática educativa. São Paulo: Paz e Terra, 2007.

G1.GLOBO. Brasil cai em ranking mundial de educação em matemática e ciências e fica estagnado em leitura. Disponível em: https://g1.globo.com/educacao/noticia/2019/12/03/brasil-cai-em-ranking-mundial-de-educacao-em-matematica-e-ciencias-e-fica-estagnado-em-leitura. ghtml. Acesso em: 20 jun. 2020.

IFPR. RESOLUÇÃO No 10, DE 11 DE MAIO DE 2020. Autoriza, em caráter excepcional, o desenvolvimento de atividades pedagógicas não presenciais nos cursos presenciais do IFPR durante o período de suspensão do calendário acadêmico como medida de prevenção e enfrentamento à disseminação da Covid-19. Disponível em: https://sei.ifpr.edu.br/sei/publicacoes/controlador_publicacoes.php?acao=publicacao_visualizar\&id_documento $=801329 \&$ id_orgao_publicacao=0. Acesso em: 12 mai. 2020.

\section{plurais}


LOPES, Alice Casimiro; MACEDO, Elizabeth. Teorias de Currículo. São Paulo: Cortez Editora, 2011.

MACHADO, Nilson José e Ubiratan D’Ambrosio [entrevista out. 2014] . Entrevista concedida ao Programa Educação Brasileira. Univesp. $n^{\circ}$ 179. Disponível em: https://www.youtube.com/ watch?v=-vRBZYw_wfw. Acesso em: 10 mai. 2020.

MILL, Daniel (org.) Dicionário Crítico de Educação e Tecnologias e de Educação a Distância. Campinas, SP: Papirus, 2018.

MOREIRA, José António; SCHLEMMER, Eliane. Por um novo conceito e paradigma de educação digital onlife. Revista UFG. V.20 (2020). Disponível em: https://www.revistas.ufg.br/ revistaufg. Acesso em: 02 jun. 2020.

SAVIANI, Nereide. Currículo: um grande desafio para o professor. Revista de Educação. N $^{\circ}$ 16. São Paulo, 2003 - pp. 35-38.

SILVA, Monica Ribeiro. O golpe no ensino médio em três atos que se completam. In: BELMIRO, Luiz; SLVA, Monica R. Democracia em Ruínas. Curitiba, CRV, 2019.

SILVA, Márcio Antônio da. Contribuições contemporâneas para as discussões curriculares em educação matemática: a teoria crítica pós-moderna. ALEXANDRIA: revista de educação em ciência e tecnologia, Florianópolis, v. 6, n. 1, p. 205-233, abril 2013. Disponível em: https://periodicos.ufsc.br/index.php/alexandria/article/view/37943. Acesso em: 26 jun. 2020.

SKOVSMOSE, O. Educação matemática crítica: a questão da democracia. Campinas: Papirus, 2001.

Recebido em: 06 de julho de 2020.

Inserido em: 10 de agosto de 2020.

Esta obra está licenciada com uma Licença Creative Commons Atribuição 4.0 Internacional. 